\title{
RESEARCH ON CHARACTERISTICS OF TURBO JET ENGINE COMBUSTION CHAMBER
}

\author{
Andrius DUBOVAS $\mathbb{D}^{*}$, Domantas BRUČAS (i) \\ Vilnius Gediminas Technical University, Vilnius, Lithuania \\ Received 28 August 2020; accepted 9 February 2021
}

\begin{abstract}
The characteristics of the combustion chamber of turbo jet engine with various parameters are examined in this article. The scientific works of other authors analyzing operating parameters of the jet engines were reviewed. Their recommendations were considered. Computer simulations of the combustion chamber were performed using different combustion reactions. The exhaust gas temperature and its dependence on the combustion mixture were determined. A practical study was also carried out, during which the experimental exhaust gas temperature was measured, and the trends of temperature change were determined. After analyzing both theoretical and practical results, the conclusions are presented.
\end{abstract}

Keywords: jet engine, combustion chamber, ANSYS CFX, exhaust gas, temperature measurement, fuel/air mixture.

\section{Introduction}

The prevalence of jet engines in the 21st century is still growing. While it is common to see these types of engines being used in aviation, there is a new tendency to use them in other areas. It was discussed in full (Isomura et al., 2004) to use them for portable energy generation. There is one more new aviation-related area where smaller jet engines could be implemented - Unmanned Aerial Vehicles (UAVs). There are few reasons for this: the first cause - smaller size and higher efficiency than the classical internal combustion piston engines. The second reason battery capacity for electric motors is currently too low for long enough flight time. In aviation, such power plants are widespread and widely studied, but there is a lack of information on low-thrust jet engines. There is not much research done using small-volume combustion chambers. Moreover, there is a lack of studies where the results obtained during computer modeling are compared with the results measured in practice. This work aims to perform computer simulations and practical tests with a small volume combustion chamber and compare theoretical and practically measured exhaust gas temperatures. The following steps had to be done: perform modeling of the combustion process and a practical test of the combustion chamber to determine the exhaust gas temperature, and compare theoretical and practical results in different operating modes. This paper aims to discover the regularities of the temperature change by using different fuel mixtures ratios. By comparing the obtained data, it is possible to evaluate how accurately the combustion temperature can be predicted at the beginning of the combustion chamber design and evaluate the differences between theoretical and practical results. An essential factor in increasing the prevalence and use of jet engines is the maximum efficiency determined by up to $50 \%$ lower size and weight. It was discussed and compared in full (Kumakura et al., 2004) to a 4-stroke internal combustion engine of the same power. It is achieved by the proper distribution of air through the individual zones of the combustion chamber. One example, which deals with air volume distribution of low-thrust jet engines, was discussed in full (Silva \& Lacava, 2013) and can be seen in Table 1 .

According to recent studies, about $50 \%$ of the combustion chamber's air is used to cool exhaust gases and the combustion chamber. It was thoroughly discussed (Alarami \& Elfaghi, 2014), the most efficient combustion process is achieved when about $33.34 \%$ of the air enters the combustion chamber through the primary zone. It was

Table 1. Air zones (source: Silva \& Lacava, 2013)

\begin{tabular}{|c|c|c|c|}
\hline Flow/zone & $\begin{array}{c}\text { Primary } \\
\text { zone }\end{array}$ & $\begin{array}{c}\text { Secondary } \\
\text { zone }\end{array}$ & $\begin{array}{c}\text { Cooling } \\
\text { zone }\end{array}$ \\
\hline Airflow - \% & 31.67 & 15.83 & 53.63 \\
\hline
\end{tabular}

${ }^{*}$ Corresponding author. E-mail: andrius.dubovas@vilniustech.lt 
discussed in full (Krieger et al., 2015) that the most significant air-fuel mixing occurs around the primary air zone. It also ensures easy ignition of the combustible mixture, relatively low $\mathrm{NO}_{\mathrm{x}}$ levels, and high combustion efficiency when operating in the low thrust range. It is also known that as the combustion temperature rises, the efficiency of the combustion chamber increases. By increasing the compressor's speed and supplying more air to the combustion chamber, combustion is more efficient. It was discussed in full by Yucer (2016). Also, with increased temperature in the combustion chamber, the turbine blades must be improved to withstand higher temperatures. It was discussed in full by Slovakian researchers (Belan et al., 2017). Another option to increase combustion efficiency but to save turbine blades from overheating is to inject cooling liquid inside a chamber. One of the examples of this method was discussed in full by Tudosie (2014). The author suggested injecting cooling liquid at the end of the chamber before exhaust gases enter the engine's turbine stage. It was also discovered that it is possible to achieve up to $25 \%$ higher engine thrust with only $15 \%$ more fuel. This topic was also fully discussed (Roumeliotis \& Mathioudakis, 2010) in a study suggested instead of a cooling liquid to use water steam to increase overall engine efficiency.

Another way to improve engine efficiency is to optimize the combustion chamber. It was discussed in full (Dong et al., 2011), and according to a practical study, by reducing the air supply openings in the combustion chamber, more stable combustion and a higher flame temperature can be achieved. It also reduces the number of $\mathrm{NO}_{\mathrm{x}}$ compounds but increases the number of $\mathrm{CO}$ and $\mathrm{CH}$ particles after the combustion process. This method allows using less fuel to produce combustion at the same temperature. Another option is to use computer software to optimize the combustion chamber. It was discussed in full (Mark \& Selwyn, 2016), where for combustion simulation, a simplified $1 \mathrm{D}-2 \mathrm{D}$ combustion chamber model was used. It allows us to obtain preliminary results faster and with less computational resources. In this case, a simplified combustion reaction that uses hydrocarbon fuel was used. The same topic was also discussed in full (Aleksandrov \& Mingazov, 2017), where a simplified combustion chamber model was used to determine the chamber's characteristics in a real-world application. Further optimization was fully discussed (Enagi et al., 2017) during later combustion chamber development stages. It is possible to perform not simplified but a fullscale simulation. However, for this method to be useful general information about combustion inside a chamber must be collected. During the optimization of the jet engines, one of the improvable areas is the fuel system. It was discussed in full (Fuchs et al., 2016), and results showed that more stable combustion is achieved with an optimized fuel system. Also, it is crucial to control fuel droplets that are injected into the chamber. It was thoroughly discussed (Keller et al., 2015), and results showed that the most effective combustion is possible when fuel droplets diameter is $d_{1}<10 \mu \mathrm{m}$. The most effective way to improve the engine's performance is to optimize not one system at a time. It was discussed in full by Davidović (2007), and study results show that the most accurate results are achieved when the fuel system and combustion chamber are optimized at the same time.

As the ecological element becomes more and more important, one of the heavily influencing engine implementation factors is the formation of harmful compounds during the combustion process. As commercial flights produce $2.6 \%$ of the world's $\mathrm{CO}_{2}$ emissions (Staples et al., 2018), it is necessary to reduce the number of pollutants. It was discussed in full by Jasiński (2019) that the Pratt \& Whitney F100-PW-229 engine releases the most harmful compounds during ground operations. Typically, the engine operates at only $15-19 \%$ of its power in this mode. Similar trends are observed in low-thrust jet engines. One of the examples is the SR30 test stand, which uses diesel fuel for the combustion. It is a low-thrust jet engine model for practical testing. It was discussed in full (Badami et al., 2013) that with increased engine speed, CO compounds' concentration decreases. As mentioned earlier, it also increases the temperature in the chamber. However, this paper's results dictate that the theoretically calculated temperature is higher than the practically measured temperature before the turbine. Also, as the engine speed increases, the difference between theoretical and practical temperatures increases.

As mentioned before, jet engines' implementation is still increasing, but the main area where they are used is commercial aviation. In general, these power plants are large and producing a massive amount of thrust. Nevertheless, smaller aircraft are starting to use jet engines. As previously mentioned, one new field, in particular, is - Unmanned Aerial Vehicles (UAVs). Those are relatively small aerial vehicles where jet engines can be implemented. For this reason, it is necessary to investigate combustion processes in small combustion chambers and compare theoretical and practical results.

\section{Combustion chamber design and manufacture}

The design of the combustion chamber starts with the evaluation of the technical characteristics of the compressor. In this case, the Garrett 1544 car turbine model was chosen, which can supply about $4 \mathrm{~kg} / \mathrm{min}$ of air when operating in the most efficient mode. This model is equipped with a radial compressor with an inducer of $32.9 \mathrm{~mm}$ in diameter. It is the main parameter that has the most significant influence on the size of the combustion chamber. The inner tube is divided into three parts: primary, secondary, and cooling zones. To maintain the combustion process and the correct temperature, a sufficient amount of air must flow through them $-31 \%, 16 \%$, and $53 \%$ of the air mass, respectively. Calculated dimensions of the designed combustion chamber (Smith, 1956):

- $98.7 \mathrm{~mm}$ inner chamber tube diameter;

- 198 mm chamber length; 
- $118.7 \mathrm{~mm}$ outer chamber tube diameter;

- $263.4 \mathrm{~mm}^{2}$ area of the primary air zone;

- $135.9 \mathrm{~mm}^{2}$ secondary air zone area;

- $450.3 \mathrm{~mm}^{2}$ cooling air zone area.

The first zone has 27 air inlets supplying air to ensure an even air supply to the combustion chamber. The second and third zones have six air inlets, respectively. By dividing the total area of the zone by the number of inlets, the areas of the required inlets are calculated:

$-9.75 \mathrm{~mm}^{2}$ inlet area in the primary zone;

- $22.65 \mathrm{~mm}^{2}$ inlet area in the secondary zone;

- $75.05 \mathrm{~mm}^{2}$ inlet area in the cooling zone.

The diameter of an inlet can be found when are of an inlet is known:

- $3.5 \mathrm{~mm}$ in the primary zone;

- $5.4 \mathrm{~mm}$ in the secondary zone;

- $9.7 \mathrm{~mm}$ in the cooling zone.

The designed combustion chamber can be seen in Figure 1.

Performed calculations are checked using JetSPECS software, designed to calculate combustion chambers when automotive turbines are used. The program generally proposes to divide the air zones in the following ratios: 30\%, 20\% and, 50\% (Fahlström \& Pihl-Roos, 2016) but based on the data of the program, it can be observed that the dimensions (length and diameter) of the combustion chamber coincide with the performed calculations.

\section{Theoretical calculations}

Version 19.3 of the CFX computer simulation software is used for theoretical calculations.

According to the program description, one of three Westbrook and Dryer - WD/WGS (Westbrook \& Dryer, 1981) hydrocarbon fuel combustion reactions can be used to model combustion processes that use propane gas as a fuel:

- Propane Air WD1;

- Propane Air WD2;

- Propane Air WGS;

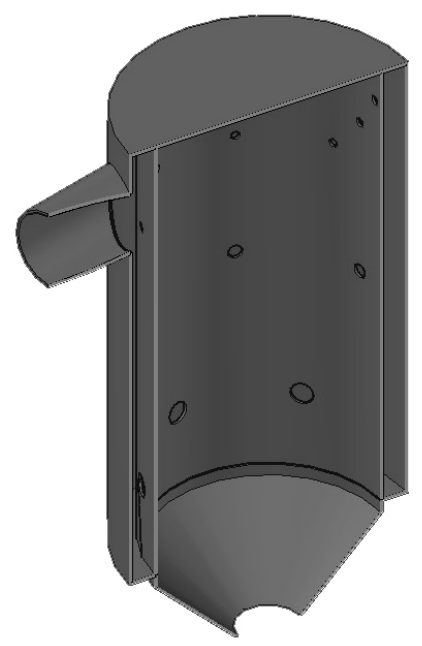

Figure1. 3D model of the combustion chamber
The most straightforward single-step reaction mechanism used in the initial calculations is WD1. This primary reaction (1) is best used at the beginning of the study to determine the flame temperature under various combustion conditions:

$$
\text { Fuel }+n_{1} \mathrm{O}_{2} \rightarrow n_{2} \mathrm{CO}_{2}+n_{3} \mathrm{H}_{2} \mathrm{O} \text {. }
$$

In this case, propane gas was used as a fuel, and previous reaction (1) can be modified according to fuel used (2):

$$
\mathrm{C}_{3} \mathrm{H}_{5}+5 \mathrm{O}_{2} \rightarrow 3 \mathrm{CO}_{2}+4 \mathrm{H}_{2} \mathrm{O} \text {. }
$$

The advantage of this calculation method is faster modeling of the combustion process. However, it should be noted that the simplicity of this method assumes that only $\mathrm{CO}_{2}$ and $\mathrm{H}_{2} \mathrm{O}$ can be present as reaction products. For this reason, the calculated flame temperature in the combustion chamber is often higher than in reality. Knowing that, in reality, hydrocarbon fuels usually burn sequentially and that not all fuel is oxidized immediately, the WD2 reaction can be used. The difference of this mechanism from the first one is that instead of one reaction (2), which accepts only $\mathrm{CO}_{2}$ and $\mathrm{H}_{2} \mathrm{O}$ as combustion products, a two-equation system is used, which allows the use of incompletely burned fuel and thus a more accurate calculation of the flame temperature in the combustion chamber. The third type of reaction is WGS. It is a simplified combustion reaction that uses water molecules. The use of this equation (3) in the combustion process makes it possible to equalize the $\mathrm{H}_{2}$ / $\mathrm{CO}$ ratio:

$$
\mathrm{CO}+\mathrm{H}_{2} \mathrm{O} \leftrightarrow \mathrm{CO}_{2}+\mathrm{H}_{2} .
$$

Depending on the parameters studied, each combustion reaction can be used with a different combustion model. The software has an option to select one out of three combustion models for each propane combustion reaction:

- Eddy dissipation model (EDM);

- Finite rate chemistry (FRC) model;

- EDM / FRC model.

In this case, combustion is simulated using an unmixed mixture - that is, the fuel and oxidizer are mixed in the combustion chamber rather than supplied already mixed before the combustion chamber. Therefore, the use of an EDM combustion model is recommended. For the initial analysis, the best option is to use the EDM model designed to study turbulent flows. One of this model's main disadvantages is that it cannot model the burning rate and flame position. The model assumes that mixing materials immediately form reaction products, and the combustion reaction itself occurs relatively faster than the transfer of materials in a gas stream (Damkohler number greater than 1). As this study aims to determine only the exhaust gas temperature, the EDM combustion model is used.

\section{Influence of the mesh}

Theoretical calculations need to be checked to see if the calculation results are affected by the mesh density. For this purpose, theoretical calculations were performed 
using a mesh of different densities. The mesh with the smallest number of elements was used in the first simulations.

This way, the initial results of what temperatures should be expected during a practical test are quickly obtained.

A mesh consisting of triangular elementary parts (elements) was used in all simulations. Tests were performed with 4 different grid settings. Table 2 shows the parameters. Tests 1 and 2 were performed with meshes with minimal differences. In experiments 3 and 4, the number of elements was increased by 12 and 15 times, respectively, and the number of nodes was increased 9 and 11 times, respectively.

After calculations with four meshes of different densities, the average calculated exhaust gas temperature is closer to the practically measured temperature using a smaller grid (Figure 2).

When performing calculations with different mesh densities, the main task is to observe how the calculated temperature interval is changing. From Figure 2 it is visible that with increasing mesh density, the average temperature decreases. When comparing the results from mesh No. 3 and No.4, a slight decrease in average temperature is visible. These results can also be compared with the WD1 reaction, and a slight increase in average temperature can be seen. At this point, there is no real need to increase mesh density further as the calculated average temperature is close to practically measured ones. Also, with increasing mesh density, more resources would be needed to perform combustion simulations. Due to these reasons for optimal combustion simulation, mesh No. 4 was chosen.

Table 2. Amount of elements and nodes

\begin{tabular}{|l|c|c|c|c|}
\hline \multicolumn{1}{|c|}{ Mesh no. } & 1 & 2 & 3 & 4 \\
\hline Nodes & 5627 & 5636 & 49743 & 59183 \\
\hline Elements & 21396 & 21402 & 260048 & 310256 \\
\hline
\end{tabular}

\section{Flammable mixtures}

It has been practically measured that the compressor can supply air to the combustion chamber at a speed of $8-30$ $\mathrm{m} / \mathrm{s}$. For the calculations, it was chosen to use two compressor modes, when the air supply is $9 \mathrm{~m} / \mathrm{s}$ and $29 \mathrm{~m} / \mathrm{s}$. It is estimated that $0.0138 \mathrm{~kg} / \mathrm{s}$ and $0.0431 \mathrm{~kg} / \mathrm{s}$ of air is supplied to the combustion chamber, respectively. These parameters will be used for combustion chamber testing. Table 3 shows the air and fuel flows and their ratio.

One test with the combustion chamber is intended to study the processes taking place in the combustion chamber in the presence of a particularly lean combustion mixture.

Temperatures measured during practical tests:

- air temperature - $283 \mathrm{~K}$;

- fuel temperature $275 \mathrm{~K}$;

This data will be used in computer simulations entering the initial data to identify the fuel and air temperature entering the combustion chamber.

\section{Methodology of practical research}

One of the biggest challenges performing the tests is very high exhaust temperature. A sensor capable of withstanding at least $1273 \mathrm{~K}$ must be used to test the broadest possible range of fuel/air ratio mixtures. For this reason, a K-type thermocouple capable of measuring temperatures in the range of 273-1297 K was used. The thermocouple is connected to the MAX6675 module, which converts the analog thermocouple signal to digital. The module must be connected to the Atmega 2560 controller that works with the Arduino software. The received digital signal

Table 3. Air and fuel flows and their ratio

\begin{tabular}{|l|c|c|c|c|}
\hline \multicolumn{1}{|c|}{ Experiment } & 1 & 2 & 3 & 4 \\
\hline Airflow $-\mathrm{kg} / \mathrm{s}$ & 0.0138 & 0.0138 & 0.0431 & 0.0431 \\
\hline Fuel flow $-\mathrm{kg} / \mathrm{s}$ & 0.000281 & 0.000032 & 0.000985 & 0.000492 \\
\hline Fuel/air ratio & $1: 50$ & $1: 431$ & $1: 44$ & $1: 88$ \\
\hline
\end{tabular}

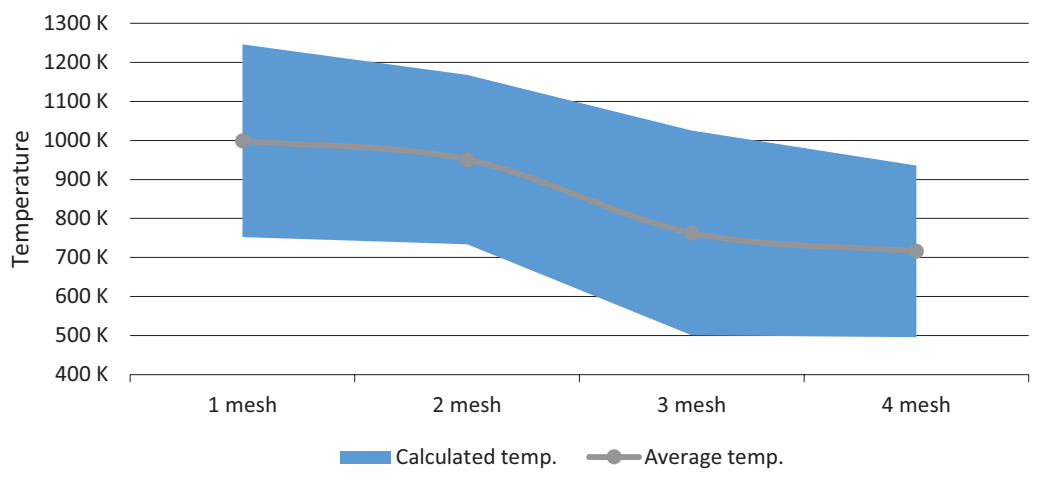

Figure 2. Mesh and temperature dependence using WGS reaction 


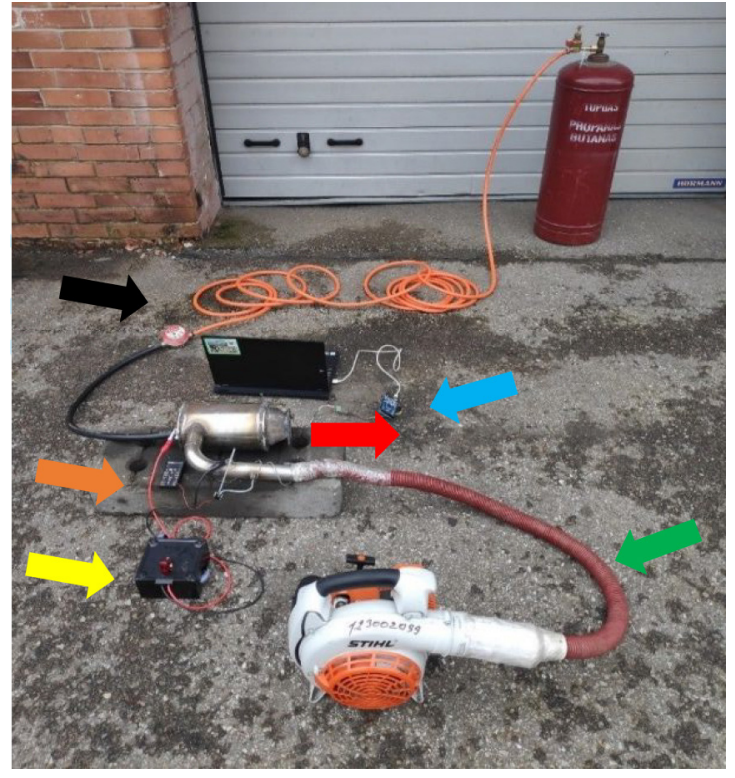

Figure 3. Black arrow - gas supply pipe with a flow meter, orange arrow - differential air pressure sensor, yellow arrow ignition module, green arrow - air pipe with compressor, blue arrow - exhaust gas temperature module, red arrow - exhaust gas flow

from the MAX6675 module, using the written program code, outputs the data to the output window with an accuracy of $0.25 \mathrm{~K}$. Figure 3 shows the equipment used for practical experiments.

Tests have shown that it is easiest to start the combustion process in a combustion chamber using low air and fuel flows. Repeated tests showed that the combustion process begins faster when the chamber is still hot.

\section{Comparison of theoretical and practical data}

When testing the combustion chamber, the tests were performed in the following sequence, starting with the richest and ending wicth the leanest mixtures. Due to the design of the temperature sensor, the average of the theoretically calculated temperature is computed. The calculated and practically measured temperatures are given in Table 4.

The first calculations were performed with the WD1 reaction. It can be seen that as the mixture ratio changes, the calculated temperatures decrease from $1233 \mathrm{~K}$ to $412 \mathrm{~K}$. Also, the range of calculated temperatures decreases. Meanwhile, the practically measured temperature, changing the mixture from 1:44 to $1: 50$, increases by $75 \mathrm{~K}$ from $898 \mathrm{~K}$ to $973 \mathrm{~K}$. As the mixture is further changed, the practically measured temperature drops to $670 \mathrm{~K}$. Using the leanest 1:431 mixture, the practically measured combustion temperature $(640 \mathrm{~K})$ exceeds the theoretically calculated temperature $(412 \mathrm{~K})$. It should be noted that when using the richest 1:44 flammable mixture, the practically measured temperature is lower than the minimum theoretical combustion temperature. This difference is equal to $29 \mathrm{~K}$.

Figure 4 shows the temperature change using the WGS reaction. The graph shows that using the richest 1:44 mixture practically measured temperature is $287 \mathrm{~K}$ lower than the average theoretical temperature. Using leaner 1:50 and 1:88 mixtures difference is significantly lower than with the richest mixture and is $77 \mathrm{~K}$ and $43 \mathrm{~K}$, respectively. Nevertheless, using the leanest 1:431 mixture practically measured temperature is higher than theoretical temperature by $280 \mathrm{~K}$. Similar temperature changes are observed with the WD2 reaction.

Table 4. Calculated and measured EGT using different reactions and mixtures

\begin{tabular}{|l|c|c|c|c|}
\hline Reaction/ratio of fuel/air mixture & $1: 44$ & $1: 50$ & $1: 88$ & $1: 431$ \\
\hline WD1 min - max temp. (K) & $927-1540$ & $670-1429$ & $549-1118$ & $351-473$ \\
\hline WD2 min - max temp. (K) & $873-1486$ & $740-1452$ & $528-1121$ & $348-452$ \\
\hline WGS min - max temp. (K) & $896-1474$ & $704-1396$ & $496-936$ & $327-390$ \\
\hline Practical temp. (K) & 898 & 973 & 673 & 643 \\
\hline
\end{tabular}

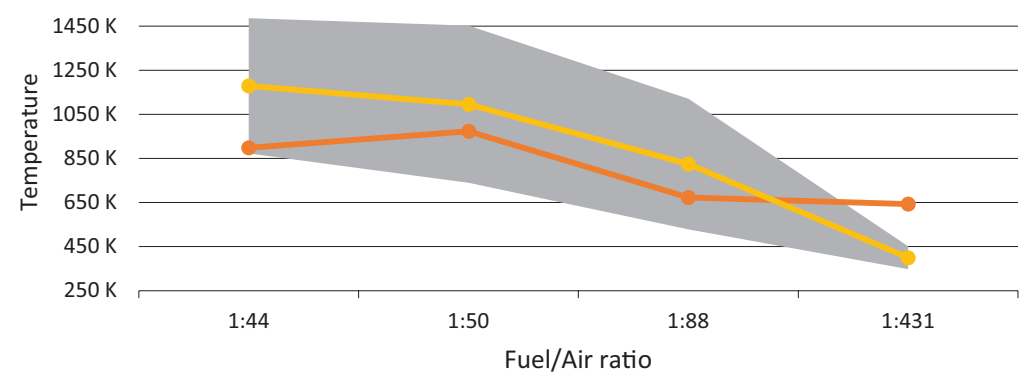

Calculated temp. $\quad$ Practical temp. $\quad$ Average calculated temp.

Figure 4. Comparison of theoretical and practical temperature using WGS reaction 


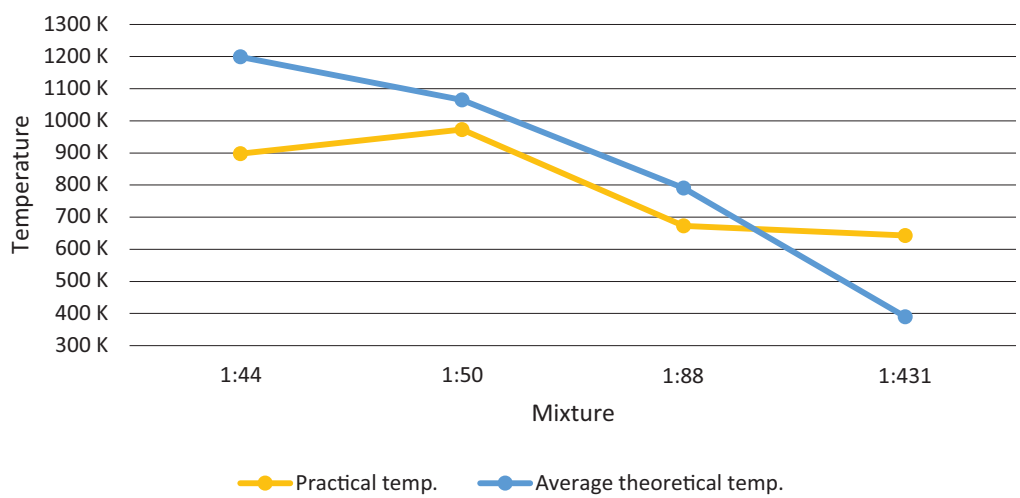

Figure 5. Comparison of average theoretical and practical temperatures

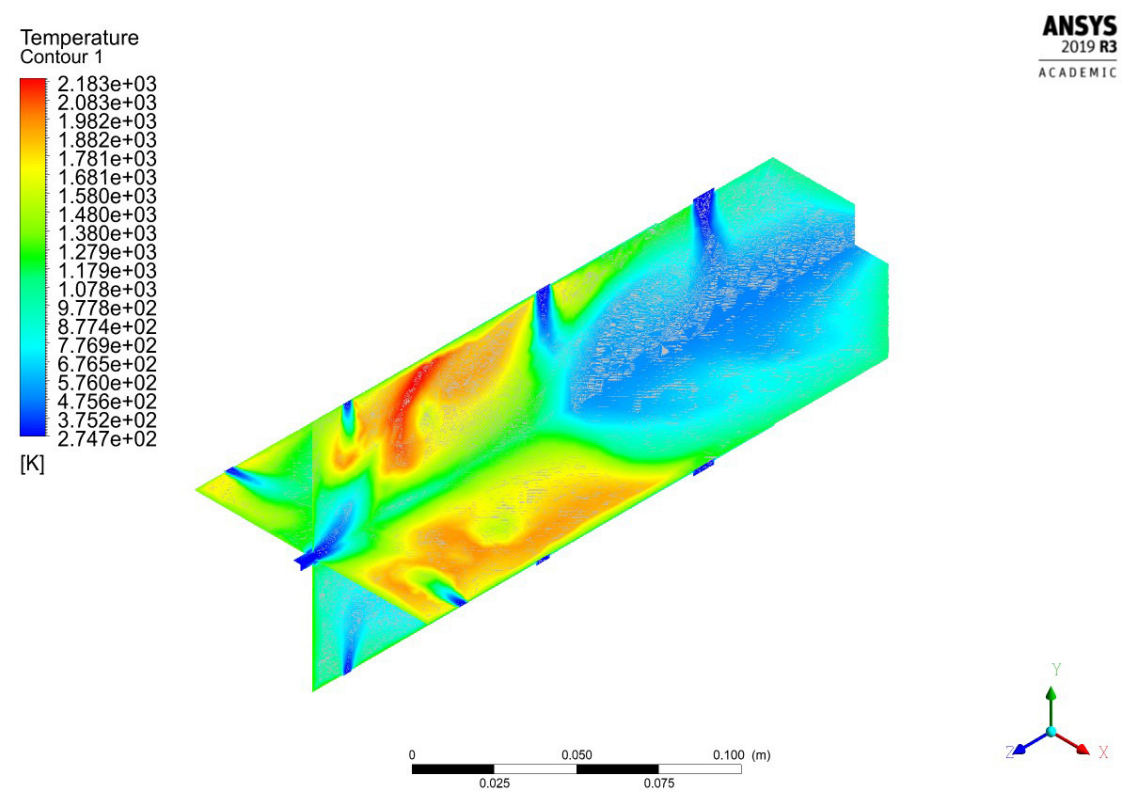

Figure 6. Temperature distribution

The graph in Figure 5 shows the average calculated temperatures using three different reactions and practically measured temperatures. It appears that with the richest mixture, the calculated temperature exceeded practical by $301 \mathrm{~K} .92 \mathrm{~K}$ temperature difference was achieved using a 1:50 mixture, and the theoretical temperature was higher by $118 \mathrm{~K}$ when using a 1:88 mixture. Opposite results can be seen with the leanest 1:431 mixture, where the practically measured temperature exceeded theoretically calculated temperature by $253 \mathrm{~K}$. As seen from these results using rich mixtures, calculated temperatures are higher than practically measured, and using lean mixtures, practically measured temperature is higher than obtained from simulations.

As shown in Figure 6, combustion is distributed over the entire area of the chamber. It allows for more even and efficient combustion. Because the amount of air from the cooling zone is sufficient, the exhaust gas is adequately cooled before entering the turbine (not present in this experiment).

\section{Analysis of computer modeling errors}

A theoretical and practical study can be used to assess which combustion reaction is most optimal to use. The results are obtained by comparing the practically measured temperature with the average of the theoretical temperature. If the difference is positive, the average temperature obtained during computer simulation is greater than the temperature measured. Otherwise, if the difference is negative, the practically measured temperature is higher than the average theoretical temperature. The results obtained are shown in Table 5.

Table 5. Differences between theoretical and practical temperatures

\begin{tabular}{|c|c|c|c|}
\hline $\begin{array}{c}\text { Ratio of fuel/air } \\
\text { mixture/Reaction }\end{array}$ & WD1 & WD2 & WGS \\
\hline $1: 44$ & $335 \mathrm{~K}$ & $281 \mathrm{~K}$ & $287 \mathrm{~K}$ \\
\hline $1: 50$ & $76 \mathrm{~K}$ & $123 \mathrm{~K}$ & $77 \mathrm{~K}$ \\
\hline $1: 88$ & $160 \mathrm{~K}$ & $151 \mathrm{~K}$ & $43 \mathrm{~K}$ \\
\hline $1: 431$ & $-231 \mathrm{~K}$ & $-243 \mathrm{~K}$ & $-284 \mathrm{~K}$ \\
\hline
\end{tabular}




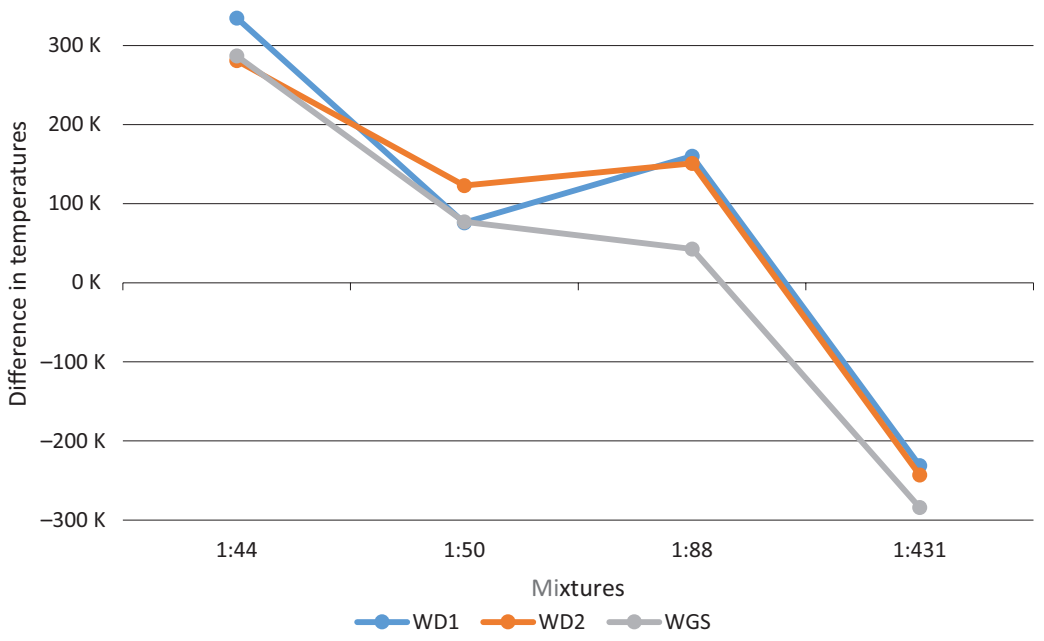

Figure 7. Temperature differences using different reactions

The data obtained can also be seen in the graph in Figure 7.

The most considerable difference between the average theoretical and practically measured temperature was determined using the richest mixture. The average temperature obtained during computer simulations is $281-335 \mathrm{~K}$ higher than the practical temperature. During the dilution of the mixture, the average of the calculated temperature approached the practically measured temperature. Using 1:50 and 1:88 mixtures, the calculated temperature exceeded the practical temperature from $43 \mathrm{~K}$ to $160 \mathrm{~K}$. The temperature difference between the reactions ranges from 47 to $117 \mathrm{~K}$. The temperature calculated using the leanest mixture is, on average, $252 \mathrm{~K}$ lower than that measured with all reactions. This 1:431 mixture was used for testing to see if combustion was theoretically possible under these conditions. It is not accurate to evaluate the data in this calculation, as the mechanical meter has noticeable errors when measuring low gas flows. For this reason, in practice, the measured gas flow may be lower than the actual gas flow. Because computer simulation requires the use of gas passage data, this can significantly affect the results which were obtained. It explains the fact that the practically measured exhaust gas temperature does not fall within the temperature range calculated during the computer simulation, as more air is devoted to the exhaust gas cooling during the calculations than during the practical test. However, a lean mixture confirms the regularity of temperature changes when the practical temperature is higher than the average theoretical temperature when using lean mixtures. While analyzing the obtained data, an observation was made that the calculated average difference between the theoretical and practical temperature is $228 \mathrm{~K}$. The average temperature difference between the combustion reactions, comparing the results obtained with the same mixtures, is $29 \mathrm{~K}$. It should be noted that one of the reasons for the difference between theoretical and practical temperature is the EDM combustion model. Comparing the ratio of temperature and fuel mixture, it can be stated that when diluting the flammable mixture, the difference between the calculated and measured temperature decreases. For the richest mixtures, the measured temperature is lower than the calculated average, and for the leanest mixtures, the practically measured temperature is higher than the theoretically calculated average temperature.

\section{Conclusions}

After performing theoretical and practical measurements of the exhaust gas temperature, the following conclusions were made:

1. Theoretical studies indicate only approximate limits of practical results. It was found that the accuracy of calculations depends on the optimization of mesh, combustion reaction, and combustion model.

2. During computer simulations, results that are closest to practical temperatures are obtained by examining mixtures that fall within the stable combustion range of fuel/air ratios of 1:30 to 1:150.

3. It was found that while using rich mixtures, the temperature obtained during computer simulations is higher than the practically measured temperature. On average, the smallest difference between practically measured and theoretical temperature was found when using WGS reaction - $135 \mathrm{~K}$. While using a lean mixture, the theoretical temperature is lower than the practically measured temperature; on average, the smallest difference between practically measured and the theoretical temperature was found when using WD1 reaction $-230 \mathrm{~K}$.

4. Further research is needed to find the exact value by which theoretically calculated temperature is higher due to EDM combustion models' effects. On average, using this model temperature using rich mixtures is $170 \mathrm{~K}$ higher than practically measured temperature. 
5. Comparing results with other authors' works shows that theoretically calculated temperature is often higher than practically measured temperature.

6 . For future research, this chamber could be investigated by imitating atmospheric conditions of a flight of an aircraft or UAV in which this type of combustion chamber could be implemented.

\section{Disclosure statement}

The authors would like to declare that they do not have any competing financial, professional, or personal interests from other parties.

\section{References}

Alarami, A. M., \& Elfaghi, A. M. (2014). Optimum design procedures of turbojet combustion chamber. In 2nd Intl'Conference on Advances in Engineering Sciences and Applied Mathematics (ICAESAM'2014) (pp. 4-5), Istanbul, Turkey.

Aleksandrov, Y. B., \& Mingazov, B. G. (2017). Optimal design of a combustion chamber of gas turbine engine by a Combustion chamber $1 \mathrm{D}-2 \mathrm{D}$ computer program. In IOP Conference Series: Materials Science and Engineering, Vol. 240, No. 1 (p. 012006). IOP Publishing.

https://doi.org/10.1088/1757-899X/240/1/012006

Badami, M., Nuccio, P., \& Signoretto, A. (2013). Experimental and numerical analysis of a small-scale turbojet engine. Energy Conversion and Management, 76, 225-233.

https://doi.org/10.1016/j.enconman.2013.07.043

Belan, J., Vaško, A., \& Kuchariková, L. (2017). A brief overview and metallography for commonly used materials in aero jet engine construction. Production Engineering Archives, 17(17), 8-13. https://doi.org/10.30657/pea.2017.17.02

Davidović, N. S. (2007). Mathematical model of turbojet engine combustion chamber primary zone. FME Transactions, 35(1), 29-34.

Dong, L. L., Cheung, C. S., \& Leung, C. W. (2011). Combustion optimization of a port-array inverse diffusion flame jet. Energy, 36(5), 2834-2846.

https://doi.org/10.1016/j.energy.2011.02.025

Enagi, I. I., Al-Attab, K. A., \& Zainal, Z. A. (2017). Combustion chamber design and performance for micro gas turbine application. Fuel Processing Technology, 166, 258-268. https://doi.org/10.1016/j.fuproc.2017.05.037

Fahlström, S., \& Pihl-Roos, R. (2016). Design and construction of a simple turbojet engine [Independent thesis, Uppsala University]. Uppsala, Sweden.

Fuchs, F., Meidinger, V., Neuburger, N., Reiter, T., Zündel, M., \& Hupfer, A. (2016, April). Challenges in designing very small jet engines-fuel distribution and atomization. In 16th Interna- tional Symposium on Transport Phenomena and Dynamics of Rotating Machinery (hal-01891309). Honolulu, United States.

Isomura, K., Tanaka, S., Togo, S., Kanebako, H., Murayama, M., Saji, N., Sato, F. and Esashi, M. (2004). Development of micromachine gas turbine for portable power generation. JSME International Journal Series B Fluids and Thermal Engineering, 47(3), 459-464. https://doi.org/10.1299/jsmeb.47.459

Jasiński, R. (2019). Jet engine stationary testing in the aspect of particles emission in real operation conditions. Transportation Research Procedia, 40, 1388-1395. https://doi.org/10.1016/j.trpro.2019.07.192

Keller, J., Gebretsadik, M., Habisreuther, P., Turrini, F., Zarzalis, N., \& Trimis, D. (2015). Numerical and experimental investigation on droplet dynamics and dispersion of a jet engine injector. International Journal of Multiphase Flow, 75, 144-162. https://doi.org/10.1016/j.ijmultiphaseflow.2015.05.004

Krieger, G. C., Campos, A. P. V., Takehara, M. D. B., Da Cunha, F. A., \& Veras, C. G. (2015). Numerical simulation of oxyfuel combustion for gas turbine applications. Applied Thermal Engineering, 78, 471-481.

https://doi.org/10.1016/j.applthermaleng.2015.01.001

Kumakura, H., Maekawa, H., \& Murakami, K. (2004). Development of portable gas turbine generator "Dynajet 2.6". IHI Engineering Review, 37, 113-114.

Mark, C. P., \& Selwyn, A. (2016). Design and analysis of annular combustion chamber of a low bypass turbofan engine in a jet trainer aircraft. Propulsion and Power Research, 5(2), 97-107. https://doi.org/10.1016/j.jppr.2016.04.001

Roumeliotis, I., \& Mathioudakis, K. (2010). Evaluation of water injection effect on compressor and engine performance and operability. Applied Energy, 87(4), 1207-1216. https://doi.org/10.1016/j.apenergy.2009.04.039

Silva, R. E. P., \& Lacava, P. T. (2013). Preliminary design of a combustion chamber for microturbine based in automotive turbocharger. In Proceedings of the 22nd COBEM (pp. 412-422).

Smith, C. W. (1956). Aircraft gas turbines. John Wiley \& Sons, Inc. Staples, M. D., Malina, R., Suresh, P., Hileman, J. I., \& Barrett, S. R. (2018). Aviation $\mathrm{CO}_{2}$ emissions reductions from the use of alternative jet fuels. Energy Policy, 114, 342-354. https://doi.org/10.1016/j.enpol.2017.12.007

Tudosie, A. N. (2014). Mathematical model for a jet engine with cooling fluid injection into its compressor. International Scientific Committee, 251-258. https://doi.org/10.1109/ICATE.2014.6972689

Westbrook, C. K., \& Dryer, F. L. (1981). Simplified reaction mechanisms for the oxidation of hydrocarbon fuels in flames. Combustion Science and Technology, 27(1-2), 31-43. https://doi.org/10.1080/00102208108946970

Yucer, C. T. (2016). Thermodynamic analysis of the part load performance for a small scale gas turbine jet engine by using exergy analysis method. Energy, 111, 251-259.

https://doi.org/10.1016/j.energy.2016.05.108 